Check for updates

Cite this: J. Mater. Chem. B, 2017, 5, 4890

Received 14th March 2017, Accepted 23rd May 2017

DOI: $10.1039 / \mathrm{c} 7 \mathrm{tb} 00708 f$

rsc.li/materials-b

\section{Presentation of functional groups on self- assembled supramolecular peptide nanofibers mimicking glycosaminoglycans for directed mesenchymal stem cell differentiation $\dagger$}

\author{
Oncay Yasa, $\ddagger^{a}$ Ozge Uysal, ${ }^{\text {ab }}$ Melis Sardan Ekiz, ${ }^{a}$ Mustafa O. Guler (D)*c and \\ Ayse B. Tekinay (iD *ab
}

\begin{abstract}
Organizational complexity and functional diversity of the extracellular matrix regulate cellular behaviors. The extracellular matrix is composed of various proteins in the form of proteoglycans, glycoproteins, and nanofibers whose types and combinations change depending on the tissue type. Proteoglycans, which are proteins that are covalently attached to glycosaminoglycans, contribute to the complexity of the microenvironment of the cells. The sulfation degree of the glycosaminoglycans is an important and distinct feature at specific developmental stages and tissue types. Peptide amphiphile nanofibers can mimic natural glycosaminoglycans and/or proteoglycans, and they form a synthetic nanofibrous microenvironment where cells can proliferate and differentiate towards different lineages. In this study, peptide nanofibers were used to provide varying degrees of sulfonation mimicking the natural glycosaminoglycans by forming a microenvironment for the survival and differentiation of stem cells. The effects of glucose, carboxylate, and sulfonate groups on the peptide nanofibers were investigated by considering the changes in the differentiation profiles of rat mesenchymal stem cells in the absence of any specific differentiation inducers in the culture medium. The results showed that a higher sulfonate-to-glucose ratio is associated with adipogenic differentiation and a higher carboxylate-to-glucose ratio is associated with osteochondrogenic differentiation of the rat mesenchymal stem cells. Overall, these results demonstrate that supramolecular peptide nanosystems can be used to understand the fine-tunings of the extracellular matrix such as sulfation profile on specific cell types.
\end{abstract}

\section{Introduction}

Regenerative medicine is a rapidly growing transdisciplinary research field for developing therapeutics. The organizational complexity and functional diversity of the cells and their surroundings are important to renew, recover, and/or regenerate tissues after a traumatic injury or a disease. The extracellular matrix (ECM) constitutes the environment surrounding the cells,

\footnotetext{
${ }^{a}$ Institute of Materials Science and Nanotechnology, National Nanotechnology Research Center (UNAM), Bilkent University, Ankara 06800, Turkey.

E-mail: mguler@uchicago.edu

${ }^{b}$ Neuroscience Graduate Program, Bilkent University, Ankara, 06800, Turkey. E-mail: atekinay@bilkent.edu.tr

${ }^{c}$ Institute for Molecular Engineering, University of Chicago, Chicago, IL 60637, USA $\dagger$ Electronic supplementary information (ESI) available: ESI-MS of PAs, HPLC chromatogram of purified PAs, SEM images of PAs, Alizarin Red-S staining of PAs at day 7 and day 14. See DOI: 10.1039/c7tb00708f

\# Current address: Physical Intelligence Department, Max Planck Institute for Intelligent Systems, Stuttgart 70569, Germany.
}

and affects cell-cell communication and survival. The ECM consists of different types of proteins, in the form of proteoglycans, glycoproteins, and long nanofibers. The composition, topology, and physicochemical characteristics of the ECM vary according to the tissue type, wound-state, and age of the organism. The natural ECM components provide a supportive microenvironment for the cells and guide their behaviors including adhesion, migration, proliferation, and differentiation. ${ }^{1}$

Glycosaminoglycans (GAGs) are highly polar, negatively charged, unbranched polysaccharides, which play important roles in various biological processes, and are vital for the recovery and regeneration of damaged tissues. They have extremely heterogeneous and complex structures due to the differences in their monomers and the degree of substitution and positioning of sulfate/sulfonate and $N$-acetyl groups. ${ }^{2}$ The GAGs have diverse intracellular and extracellular functions, and play crucial roles in different biological processes including growth, proliferation, and differentiation of the cells, regeneration of nerve, cartilage and bone tissues, angiogenesis, and tumor metastasis through specific 
interactions with growth factors, growth factor receptors, extracellular matrix proteins, and other chemokines. ${ }^{3-7}$ In the ECMs of mammalian tissues, the GAGs excluding hyaluronan are found covalently attached to proteins, classified as proteoglycans. ${ }^{8}$ Regulation of expression and sulfation levels of ECM proteoglycans is important for determining the differentiation fate of the mesenchymal stem cells (MSCs). ${ }^{9}$

MSCs are stromal cells that have the ability to self-renew and/or differentiate into mesodermal (bone, adipose, and cartilage) and non-mesodermal lineages in culture. ${ }^{10-13}$ MSCs are attractive candidates for regenerative medicine studies because they can be easily isolated, and have broad differentiation potentials. $^{14}$ Previous studies have demonstrated that the proliferation and differentiation of the MSCs can be controlled with exogenous application of GAGs. For example, the exogenous application of heparan sulfate to rat MSCs caused an increase in the proliferation of the cells and also stimulated the expression of osteogenic markers and bone nodule formation. ${ }^{15}$ Previously, supplementation with an embryonic form of heparan sulfate was shown to enhance self-renewal of human MSCs and to induce their ex vivo expansions. ${ }^{16}$ It is known that the differentiation lineages of human MSCs can be controlled and induced by using synthetic matrices functionalized with distinct chemical groups. ${ }^{17}$ Finally, it is also important to note that besides the chemical composition of the synthetic matrices or natural microenvironments, physical cues including material stiffness, shear stress, and electrical and magnetic forces also play important roles in stem cell differentiation. ${ }^{18,19}$

Peptide amphiphile (PA) nanofibers are attractive materials for directing stem cell differentiation due to their self-assembly capacities into high-aspect-ratio nanofibers, which resemble the natural ECM microenvironment. ${ }^{20-26}$ The PA molecules consist of a hydrophobic domain, a short peptide sequence, which plays a role in the formation of intermolecular hydrogen bonds, and a charged residue that enhances the solubility of the molecule in water and assists $\mathrm{pH}$ and electrolyte responsive nanostructures. ${ }^{21,27,28}$ The bioactive peptide epitope, which is usually designed by mimicking functional epitopes of proteins, is used for providing special signals for the adhesion, proliferation and differentiation of the cells and forms the fourth region. ${ }^{28}$ The PA molecules form bioactive supramolecular assemblies, which enable the manipulation of the cellular behavior both in vitro and in vivo in terms of adhesion, proliferation, and differentiation. ${ }^{29-35}$

In this study, we constructed functional nanofibrous networks to mimic natural GAGs and to systematically investigate the effect of sulfonation of the ECM on MSCs. The differentiation potentials of rat MSCs towards mesodermal lineages were analyzed over sulfonate-rich and carboxylate-rich nanofibrous networks. The nanofiber networks that contained a higher sulfonate-toglucose ratio directed rat MSCs towards adipogenic differentiation, while the nanofiber networks that contained a higher carboxylateto-glucose ratio were observed to direct differentiation of rat MSCs towards the osteochondrogenic lineage. Overall, these results demonstrate that rational design of supramolecular peptide systems can provide efficient platforms for manipulation of stem cell fate in vitro.

\section{Experimental}

\section{Materials}

9-Fluorenylmethoxycarbonyl (Fmoc) and tert-butoxycarbonyl (Boc) protected amino acids except glyco amino acid, [4-[ $\alpha-\left(2^{\prime}, 4^{\prime}-\right.$ dimethoxyphenyl)Fmoc-aminomethyl]phenoxy] acetamidonorleucylMBHA resin (Rink amide MBHA resin), Fmoc-Glu(OtBu)-Wang resin, and 2-(1H-benzotriazol-1-yl)-1,1,3,3-tetramethyluronium hexafluorophosphate (HBTU) were purchased from NovaBiochem and ABCR. Fmoc-Ser[ $\beta$-Glc(OAc)4]-OH was purchased from AAPPTec. $N, N$-Diisopropylethylamine (DIEA) and lauric acid were purchased from Merck. Piperidine, acetic anhydride, dichloromethane (DCM), dimethylformamide (DMF), trifluoroacetic acid (TFA), and triisoproplysilane (TIS) were purchased from Sigma-Aldrich. The other chemicals were purchased from Fisher and/or Alfa Aesar and all the chemicals were used as provided.

Dulbecco's Modified Eagle medium (DMEM), penicillin/ streptomycin (PS) antibiotic combination, and fetal bovine serum (FBS) were purchased from Gibco, Life Technologies. AlamarBlue ${ }^{\circledR}$ was purchased from Invitrogen. BrdU (colorimetric) was purchased from Roche. Safranin-O, Oil Red-O, and Alizarin Red-S were purchased from Sigma-Aldrich. For the protein expression analyses of the rat MSCs, the flow cytometry kit was purchased from BD Biosciences and collagenase (Type I Powder) was purchased from ThermoFisher Scientific. All the antibodies were purchased from Abcam.

\section{Synthesis of peptide amphiphile molecules}

Peptide amphiphile molecules were synthesized by using the standard solid phase peptide synthesis method with Rink amide MBHA resin or glutamic acid loaded Wang resin. Glc-PA [Lauryl-VVAGKS( $\beta$-Glc)-Am], $\mathrm{SO}_{3}$-PA [Lauryl-VVAGEK $(p$ sulfobenzoate)-Am] and K-PA [Lauryl-VVAGK-Am] were synthesized on Rink amide MBHA resin. E-PA [Lauryl-VVAGE] was synthesized on 0.72 mmole $^{\mathrm{g}^{-1}}$ loaded Fmoc-Glu-Wang resin which was prepared by preloading 1.1 mmole $\mathrm{g}^{-1}$ loaded Wang resin with Fmoc-Glu(OtBu)-OH. Prior to the first coupling reaction, the resins were swelled in DCM and then the solvent was exchanged to DMF, in which all the remaining reactions were carried out. In the synthesis of every PA molecule, the solid phase was washed three times with DMF, three times with DCM, and finally again three times with DMF between each step for removing unreacted chemicals. Each coupling reaction started with Fmoc protecting group removal by using $20 \%(\mathrm{v} / \mathrm{v})$ piperidine/DMF solution for $20 \mathrm{~min}$. Amino acids were prepared for the coupling reaction by dissolving in DMF. The amino acid coupling reactions were performed by using 2 equivalents of amino acid, 1.95 equivalents of HBTU and 3 equivalents of DIEA in $10 \mathrm{~mL}$ of DMF. At the end of this step, the completeness of the coupling reaction was determined with the Kaiser test. $10 \%(\mathrm{v} / \mathrm{v})$ acetic anhydride/DMF solution was used in order to acetylate the unreacted amine groups. These steps were repeated until the desired amino acid sequences were obtained, lauric acid addition was done similarly to the amino acid coupling reaction at the end. After the synthesis procedure, peptide cleavage from the solid phase was carried out at room temperature with $95 \%$ 
cleavage cocktail ( $95: 2.5: 2.5$ TFA: TIS : $\mathrm{ddH}_{2} \mathrm{O}$ ), and subsequently excess TFA and DCM were removed with a rotary evaporator. Ice cold diethyl ether was added to precipitate the remaining PA solution, and left overnight at $-20{ }^{\circ} \mathrm{C}$. On the next day, the solution was centrifuged at $8000 \mathrm{rpm}$ to completely precipitate the PA molecules, diethyl ether was decanted, the remaining was evaporated, and the PA molecules were dissolved in $\mathrm{ddH}_{2} \mathrm{O}$. The PA solution was frozen at $-80{ }^{\circ} \mathrm{C}$, and then lyophilized and stored at $-20{ }^{\circ} \mathrm{C}$.

\section{Liquid chromatography-mass spectrometry (LC-MS)}

A quadruple time of flight (Q-TOF) mass spectrometer with an electrospray ionization (ESI) source equipped for reverse phase analytical high performance liquid chromatography was used to characterize the synthesized PA molecules. For the characterization of the negatively and positively charged PA molecules, an Agilent Zorbax Extend-C18 $(2.1 \times 50 \mathrm{~mm})$ column and a Zorbax SB-C8 $(4.6 \times 100 \mathrm{~mm})$ column were used as stationary phases, respectively. A gradient of water $\left(0.1 \%\right.$ formic acid or $\left.0.1 \% \mathrm{NH}_{4} \mathrm{OH}\right)$ and acetonitrile ( $0.1 \%$ formic acid or $0.1 \% \mathrm{NH}_{4} \mathrm{OH}$ ) was used as the mobile phase during liquid chromatography. Reverse phase preparative high pressure liquid chromatography (HPLC) equipped with either a Zorbax Extend-C18 $(21.2 \times 150 \mathrm{~mm})$ column or a Zorbax SB-C8 $(21.2 \times 150 \mathrm{~mm})$ column as a stationary phase was used to purify negatively and positively charged PA molecules, respectively. A gradient of water $\left(0.1 \%\right.$ TFA or $\left.0.1 \% \mathrm{NH}_{4} \mathrm{OH}\right)$ and acetonitrile $\left(0.1 \%\right.$ TFA or $\left.0.1 \% \mathrm{NH}_{4} \mathrm{OH}\right)$ was used as the mobile phase during the HPLC purification of the synthesized PA molecules.

\section{Circular dichroism (CD)}

A J-815 Jasco spectrophotometer in the far ultra-violet region was used for analyzing the secondary structures of the PA molecules. The PA molecules were prepared and used at a final concentration of $200 \mu \mathrm{M}$ during all analyses. A quartz cuvette with $1 \mathrm{~mm}$ path length was used for all the measurements and the measurement parameters were selected as: digital integration time of $1 \mathrm{~s}$, band width of $1 \mathrm{~nm}$, data pitch of $0.1 \mathrm{~nm}$, and with standard sensitivity. The scanning was done with an average of three readings between $190 \mathrm{~nm}$ and $300 \mathrm{~nm}$. Ellipticity data obtained from measurements were converted to molar ellipticity with the unit degree $\mathrm{cm}^{2}$ mole $^{-1}$.

\section{Scanning electron microscopy (SEM)}

PA nanofiber networks were analyzed by using scanning electron microscopy. The SEM samples were prepared by mixing $10 \mathrm{mM}$ Glc-PA and $10 \mathrm{mM} \mathrm{SO}_{3}-\mathrm{PA}$ at $1: 1$ ratio, $10 \mathrm{mM}$ Glc-PA, $10 \mathrm{mM}$ E-PA and $10 \mathrm{mM} \mathrm{SO}$-PA at $2: 1: 1$ ratio, $10 \mathrm{mM}$ Glc-PA and $10 \mathrm{mM}$ E-PA at $1: 1$ ratio, and finally $10 \mathrm{mM} \mathrm{K}-\mathrm{PA}$ and $10 \mathrm{mM}$ E-PA at 1:1 ratio to have overall negatively charged hydrogels. The hydrogels were placed onto silicon wafers and incubated for 30 min before applying the serial ethanol dehydration protocol. The hydrogels were dehydrated sequentially in $20 \%$ (v/v), $40 \%(\mathrm{v} / \mathrm{v})$, $60 \%(\mathrm{v} / \mathrm{v}), 80 \%(\mathrm{v} / \mathrm{v})$ and absolute ethanol, and dried by using a critical point dryer (Tousimis, Autosamdri-815B, Series C critical point dryer). The samples were coated with $5 \mathrm{~nm}$
$\mathrm{Au} / \mathrm{Pd}$ and analyzed by using SEM (FEI Quanta 200 FEG) with an ETD detector at high vacuum mode at $10 \mathrm{keV}$ beam energy.

\section{Transmission electron microscopy (TEM)}

A FEI Tecnai G2 F30 transmission electron microscope was used to analyze the structure of the PA nanofibers at the nanoscale. Lacey mesh ultrathin carbon coated copper grids were used for TEM analysis. The TEM samples were prepared by mixing $2 \mathrm{mM}$ Glc-PA and $2 \mathrm{mM} \mathrm{SO}_{3}$-PA at 1:1 ratio, $2 \mathrm{mM}$ Glc-PA, $2 \mathrm{mM}$ E-PA and $2 \mathrm{mM} \mathrm{SO}_{3}$-PA at $2: 1: 1$ ratio, $2 \mathrm{mM}$ Glc-PA and $2 \mathrm{mM}$ E-PA at $1: 1$ ratio, and $2 \mathrm{mM} \mathrm{K-PA}$ and $2 \mathrm{mM}$ E-PA at $1: 1$ ratio to have overall negatively charged networks. The upper part of the grids was dipped into the samples that were diluted 100 times with distilled water for $1 \mathrm{~min}$ and then stained with $2 \mathrm{wt} \%$ uranyl acetate for $40 \mathrm{~s}$. The samples were kept in a fume hood until a dried film was obtained. The STEM images were obtained with a FEI Tecnai G2 F30 TEM, but at HAADF mode. All the TEM and STEM images were acquired at $300 \mathrm{kV}$.

\section{Maintenance of cell culture}

Cell culture experiments including viability, proliferation, differentiation, and protein expression analysis were performed by using rat MSCs (Invitrogen, passage number 6-8). The cells were incubated at $37{ }^{\circ} \mathrm{C}$ in a humidified atmosphere supplied with $5 \% \mathrm{CO}_{2}$ in low glucose DMEM supplemented with $10 \%$ fetal bovine serum (FBS) and 1\% penicillin/streptomycin (PS). Cell culture was performed in $75 \mathrm{~cm}^{2}$ flasks and cells were seeded in these flasks at 3000 cells per $\mathrm{cm}^{2}$ density. The cell mediun was replenished every 3 days and the cells were used in experiments or subcultured when they reached $\sim 90 \%$ confluency.

\section{Cell viability and proliferation}

Cell viability and proliferation analyses were performed by seeding rat MSCs onto PA-coated and uncoated wells. 96-Well plates were used for all the analyses and the wells were coated with $10 \mathrm{mM}$ Glc-PA and $10 \mathrm{mM} \mathrm{SO}_{3}$-PA at a $1: 1$ ratio for the Glc-PA/SO $\mathrm{SO}_{3}$-PA group; $10 \mathrm{mM}$ Glc-PA, $10 \mathrm{mM}$ E-PA and $10 \mathrm{mM}$ $\mathrm{SO}_{3}-\mathrm{PA}$ at a $2: 1: 1$ ratio for the Glc-PA/E-PA/SO $\mathrm{SO}_{3}-\mathrm{PA}$ group; $10 \mathrm{mM}$ Glc-PA and $10 \mathrm{mM}$ E-PA at a $1: 1$ ratio for the Glc-PA/ E-PA group; and $10 \mathrm{mM}$ K-PA and $10 \mathrm{mM}$ E-PA at a $1: 1$ ratio for the K-PA/E-PA group. This coating system was used for all the cell culture experiments mentioned below. The cells were seeded at a density of $15.6 \times 10^{3}$ cells per $\mathrm{cm}^{2}$. The rat MSCs were seeded in low glucose DMEM supplemented with 10\% FBS and $1 \%$ PS under $5 \% \mathrm{CO}_{2}$ at $37{ }^{\circ} \mathrm{C}$ in a humidified atmosphere. The cytotoxicity of the PA nanofiber networks was evaluated by using Alamar Blue (Invitrogen) at $24 \mathrm{~h}$. The medium was discarded and the cells were washed with phosphate buffered saline (PBS). Then, the cells were incubated with $10 \%(\mathrm{v} / \mathrm{v})$ Alamar Blue in serum free media for $4 \mathrm{~h}$. The absorbance at $570 / 600 \mathrm{~nm}$ excitation/emission was measured with a microplate reader (Molecular Devices Spectramax M5). The absorbance values were normalized to uncoated wells. Proliferation of the rat MSCs on PA nanofiber networks was evaluated by using BrdU (colorimetric) at $72 \mathrm{~h}$. At the end of $70 \mathrm{~h}$, the medium was discarded and then the cells were incubated with standard cell 
culture medium supplemented with $100 \mu \mathrm{M}$ BrdU labeling solution for $2 \mathrm{~h}$. The BrdU incorporation assay was performed according to the manufacturer's protocol.

\section{Cell adhesion and spreading}

Cell adhesion analyses were performed by seeding rat MSCs onto PA-coated and uncoated wells. 96-Well plates were used for the analysis and the wells were coated in the same manner as described above. The cells were seeded at a density of $2.0 \times 10^{3}$ cells per well. The adhesion analysis was performed in adhesion medium which is primarily a serum free medium containing $50.0 \mu \mathrm{g} \mathrm{mL}^{-1}$ cyclohexamide and $4.0 \mathrm{mg} \mathrm{mL}^{-1}$ BSA. Before seeding the cells onto the PA-coated and uncoated wells, they were incubated in the adhesion medium for $1 \mathrm{~h}$. After that, they were seeded into the wells again in the adhesion medium. At the end of the $5 \mathrm{~h}$ incubation period, the cells were washed with $1 \times$ PBS and the adherent cells were stained with Calcein for $20 \mathrm{~min}$. Finally, the adherent cells were investigated using a fluorescence microscope and the analysis was performed using Image J. Spreading of the rat MSCs on the PA nanofiber networks was evaluated by staining the cells with Phalloidine/ TO-PRO (Invitrogen) $(1: 500 / 1: 1000)$. Glass cover slips that fit into 24-well plates were used for the analysis and the cells were seeded at a density of $10.0 \times 10^{3}$ cells per well in maintenance medium. Images were taken with a confocal microscope and analyzed using Image $\mathrm{J}$.

\section{Mineral deposition analysis with Alizarin Red-S staining}

Alizarin Red-S staining was performed at the end of day 7 and day 14 as previously described. ${ }^{36}$ 96-well plates that were PA-coated and uncoated were used for determining the mineralized nodule formation and calcium deposition ability of the rat MSCs. Briefly, the medium was discarded and the cells were washed with PBS. Then, the cells were fixed with ice-cold $70 \%(\mathrm{v} / \mathrm{v})$ ethanol for $1 \mathrm{~h}$ at room temperature and washed with $\mathrm{dd}_{2} \mathrm{O}$ on a shaker for $15 \mathrm{~min}$. The cells were stained with $40 \mathrm{mM}$ Alizarin Red S solution ( $\mathrm{pH} 4.2$ ) for $30 \mathrm{~min}$ at room temperature on a shaker. The Alizarin Red-S solution was then discarded and the wells were washed with $\mathrm{ddH}_{2} \mathrm{O} 5$ times to get rid of nonspecific binding of the dye. The stained calcium nodules were observed under a light microscope and images were acquired at $10 \times$ magnification. To quantify Alizarin Red-S staining, the wells were destained by using $10 \%$ (w/v) cetylpyridinium chloride in $10 \mathrm{mM}$ sodium phosphate for $15 \mathrm{~min}$ at room temperature and the absorbance was read at $562 \mathrm{~nm}$ by using a microplate reader.

\section{Sulfated glycosaminoglycan deposition analysis}

Sulfated GAG deposition was assessed by performing Safranin-O staining at the end of day 7 and day 14. Safranin-O staining was performed by using 96-well plates that were PA-coated and uncoated. Briefly, the medium was discarded and the cells were washed with $1 \times$ PBS. After the washing step, the cells were fixed by using $10 \%(\mathrm{v} / \mathrm{v})$ formalin in PBS for $15 \mathrm{~min}$ at room temperature. The cells were washed with $1 \times$ PBS, and blocked with $1 \%(\mathrm{w} / \mathrm{v}) \mathrm{BSA} / \mathrm{PBS}$ for $30 \mathrm{~min}$ at room temperature. After destaining with $0.1 \%(\mathrm{w} / \mathrm{v})$ Safranin-O in $1 \%(\mathrm{v} / \mathrm{v})$ acetic acid for $5 \mathrm{~min}$ at room temperature, the wells were extensively washed 3 times with $0.1 \%(\mathrm{v} / \mathrm{v})$ acetic acid in PBS to remove unbound dye and stained GAG deposition was observed under a light microscope.

\section{Lipid deposition analysis with Oil Red-O staining}

Lipid deposition and lipid vacuoles were assessed by using Oil Red-O staining at the end of day 7 and day 14. Oil Red-O staining was performed by using 96-well plates that were PA-coated and uncoated. Briefly, the medium was discarded and the cells were washed with $1 \times$ PBS, and incubated with $10 \%(\mathrm{v} / \mathrm{v})$ formalin in PBS for $10 \mathrm{~min}$ at room temperature. The cells were fixed by replacing the formalin with fresh formalin and incubating for an additional $1 \mathrm{~h}$ at room temperature. The wells were washed with $\mathrm{ddH}_{2} \mathrm{O}$ and incubated with $60 \%(\mathrm{v} / \mathrm{v})$ isopropanol for $5 \mathrm{~min}$ at room temperature. The isopropanol was then removed and the wells were completely air dried. The cells were stained with Oil Red-O working solution for $10 \mathrm{~min}$ at room temperature and washed 4 times with $\mathrm{ddH}_{2} \mathrm{O}$. The images were acquired under a light microscope at $100 \times$ magnification. For the quantification of Oil Red-O staining, Oil Red-O dye was eluted by incubating the cells with absolute isopropanol for $10 \mathrm{~min}$ at room temperature with gentle shaking. After that, absorbance was measured at $500 \mathrm{~nm}$ by using $100 \%$ isopropanol as a blank.

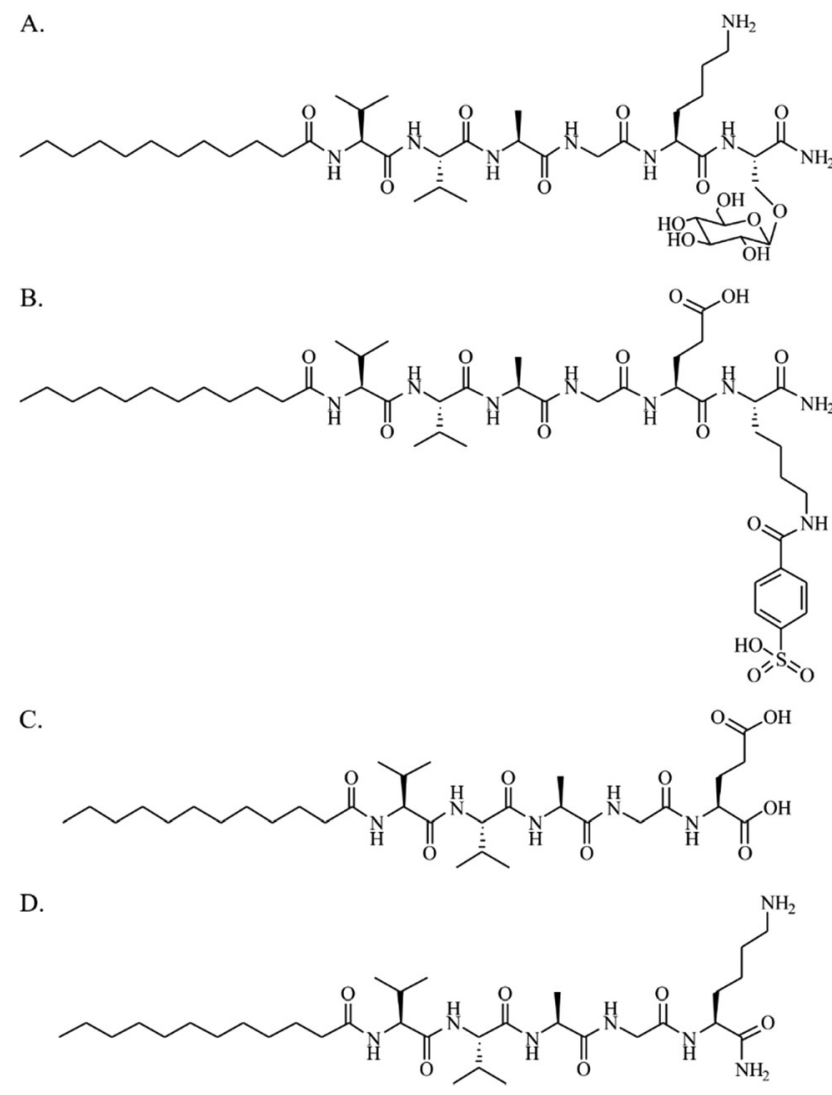

Fig. 1 Chemical representations of PA molecules. (A) Glc-PA [LaurylVVAGKS( $\beta$-Glc)-Am], (B) $\mathrm{SO}_{3}$-PA [Lauryl-VVAGEK( $p$-sulfo benzoate)-Am], (C) E-PA [Lauryl-VVAGE], and (D) K-PA [Lauryl-VVAGK-Am]. 
Paper
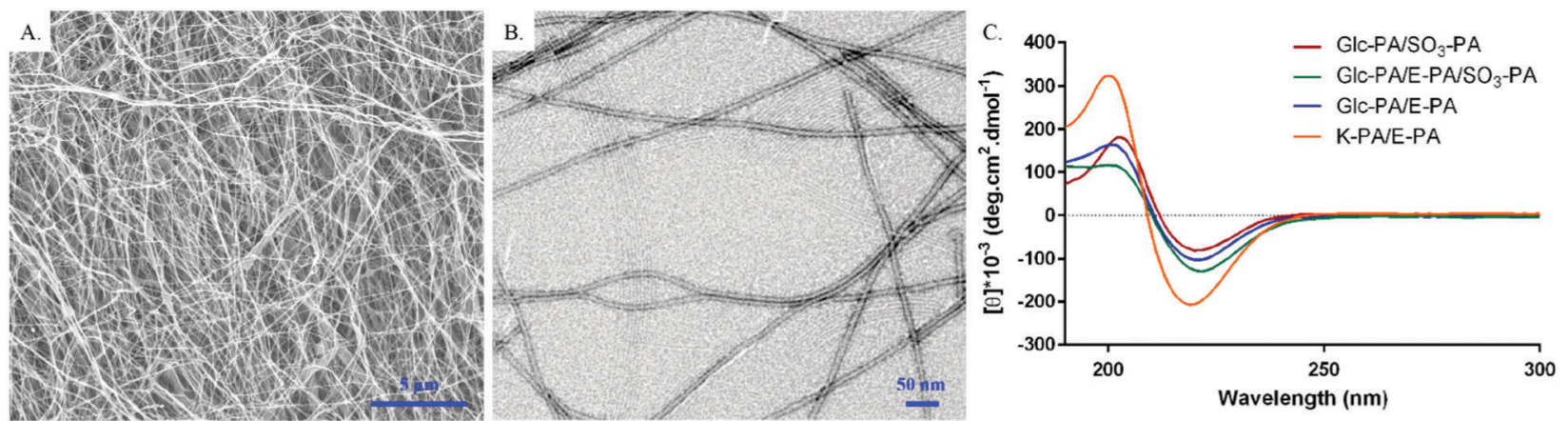

Fig. 2 Characterization of PA nanofibers. (A) SEM image of Glc-PA/E-PA revealed the fibrous nature of the network, (B) TEM image of Glc-PA/E-PA demonstrated the diameter and morphology of each nanofiber. (C) Circular dichroism spectra of PA nanofibers showed that the secondary structures primarily consisted of $\beta$-sheets.

A.

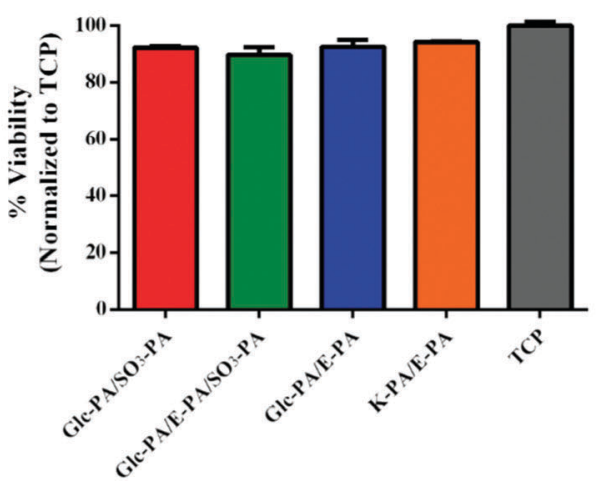

B.

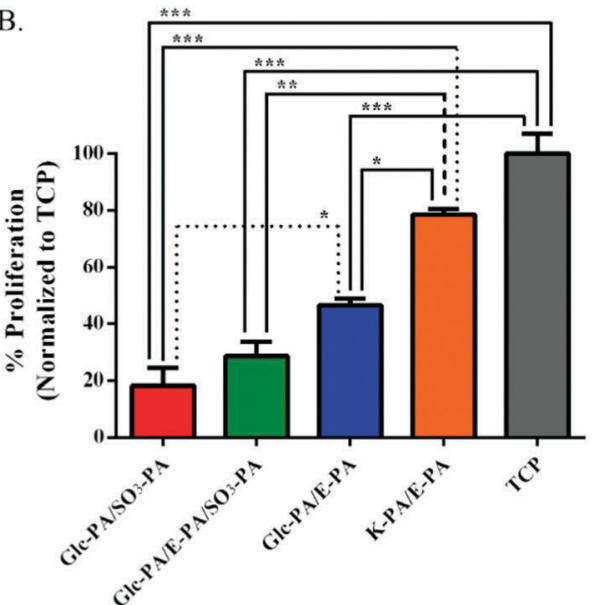

Fig. 3 Biocompatibility analyses of PA nanofiber networks. (A) Viability of rat MSCs on different PA nanofiber networks and uncoated TCP. AlamarBlue ${ }^{\mathbb{R}}$ was used to quantitatively determine the viability of the rat MSCs at $24 \mathrm{~h}$. (B) Proliferation of rat MSCs cultured with BrdU (colorimetric) on different PA nanofiber networks and uncoated TCP at $72 \mathrm{~h}$. One-way ANOVA with the Tukey post-test was applied for analyzing the results and significant differences (*) were expressed as $p<0.05$. $(n=4)$.

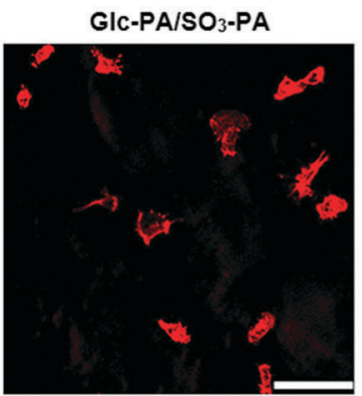

K-PA/E-PA

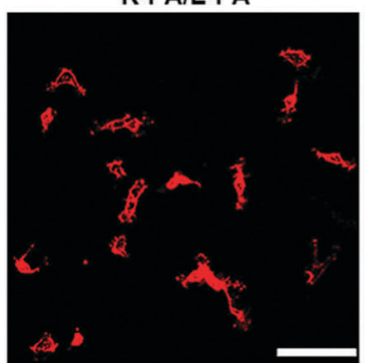

\section{GIC-PA/E-PA/SO 3 -PA}

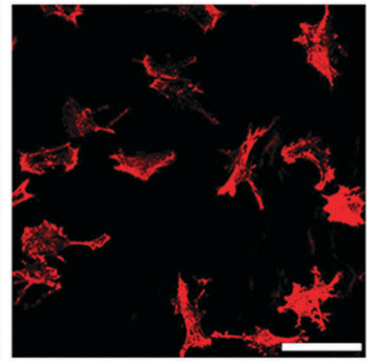

TCP

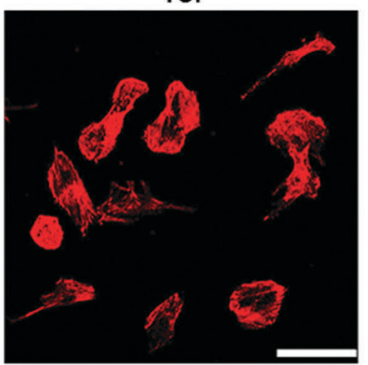

GIC-PA/E-PA

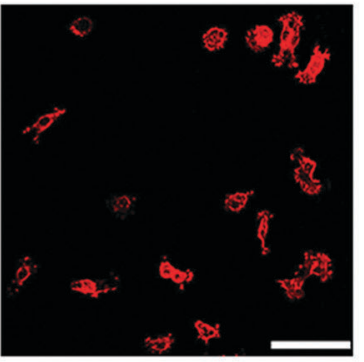

Cellular Spreading

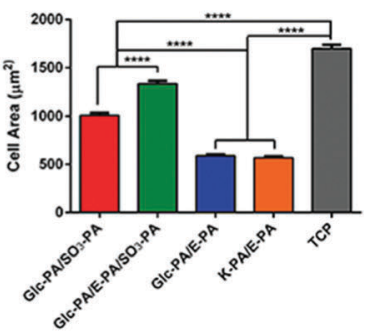

Fig. 4 Quantification of cellular spreading of rat MSCs $24 \mathrm{~h}$ after seeding on PA nanofiber networks and uncoated TCP, and representative confocal microscope images of phalloidine stained rat MSCs $24 \mathrm{~h}$ after seeding on PA nanofiber networks. One-way ANOVA with the Tukey post-test was applied for analyzing the results and significant differences $\left(^{*}\right)$ were expressed as $p<0.05$. $(n=50)$ (scale bar $\left.=100 \mu \mathrm{m}\right)$. 


\section{Alkaline phosphatase activity assay}

Protein and alkaline phosphatase activity assays were performed by using 48-well plates that were PA-coated and uncoated. Briefly, the cells were washed with $1 \times$ PBS prior to protein extraction. Protein extraction was performed first by adding PEK (Protein Extraction Kit)/PIK (Protease Inhibitor Cocktail) at a $95: 5$ ratio onto the cells and incubating on a shaker for $30 \mathrm{~min}$. Then, the cells were lysed by vortexing, and protein samples containing solutions from each well were transferred into Eppendorf tubes by pipetting. The protein samples were centrifuged at $14000 \mathrm{~g}$ at $4{ }^{\circ} \mathrm{C}$ for $10 \mathrm{~min}$ and the supernatants that contain proteins were taken into new Eppendorf tubes. A Pierce ${ }^{\circledR}$ BCA protein assay (Thermo Scientific) was performed to quantify the protein amount obtained from the cells as described in the manufacturer's protocol. Absorbance was determined at $562 \mathrm{~nm}$ by using a microplate reader (Molecular Devices Spectramax M5). For the analysis of the alkaline phosphatase activity of the cells, $50 \mu \mathrm{L}$ of protein sample obtained from the protein assay was incubated with $150 \mu \mathrm{L}$ of $p$-nitrophenol phosphate substrate in a 96-well plate for $30 \mathrm{~min}$ on a shaker. Serial dilutions of $p$-nitrophenol in $0.25 \mathrm{M} \mathrm{NaOH}$ were used as standards. Finally, the optical density was determined at $405 \mathrm{~nm}$ wavelength by using an M5 microplate reader. The alkaline phosphatase activity values were normalized to the total protein amount.

\section{Protein expression analyses with flow cytometry}

Flow cytometry analyses were performed to further understand the differentiation path of the rat MSCs cultured on different PA nanofiber networks. For this purpose, the expression levels of SOX9, Runx2, and C/EBP- $\alpha$ proteins were investigated to evaluate the osteo/chondrogenic or adipogenic differentiation of the cells on PA nanofiber networks and TCP. Before the flow cytometry analyses, rat MSCs were detached from the PA nanofiber networks or TCP surfaces using collagenase/trypsin treatment. This cell supernatant was collected and centrifuged at $2500 \mathrm{rpm}$ for $5 \mathrm{~min}$, then the cell pellet was washed twice with $1 \times$ PBS. After washing steps, the cells were fixed with $4 \%(\mathrm{v} / \mathrm{v})$ paraformaldehyde for $15 \mathrm{~min}$ on ice. The solution was centrifuged at $2500 \mathrm{rpm}$ for $5 \mathrm{~min}$. For the permeabilization process, the cells were resuspended and incubated with $0.2 \%(\mathrm{v} / \mathrm{v})$ Tween-20/PBS for $15 \mathrm{~min}$ on ice. The antibody solutions were diluted in $3 \%(\mathrm{w} / \mathrm{v}) \mathrm{BSA} / \mathrm{PBS}$, according to the concentrations that are recommended by the manufacturer (Abcam). To evaluate whether the cells are committing to the osteogenic or chondrogenic lineage, anti-Runx2 antibody (ab40764) and anti-SOX9 antibody (ab185230) were used respectively, and to evaluate whether the cells are committing to the adipogenic lineage, anti-C/EBP- $\alpha$ antibody (ab40764) was used. After $1 \mathrm{~h}$ of antibody staining, the cells were washed with permeabilization buffer, centrifuged and incubated with the corresponding secondary antibodies [Goat Anti-Rabbit IgG H\&L (Cy5) pre-adsorbed (ab97077) for C/EBP- $\alpha$ and SOX9, and Goat Anti-Mouse IgG H\&L (Alexa Fluor 488) (ab150113) for Runx2] for $1 \mathrm{~h}$ on ice. After washing with the permeabilization solution twice, the cells were pelleted and resuspended with $1 \times$ PBS for the flow cytometry measurements. A BD AccuriTM C6 flow cytometer system was used for the analyses.

\section{Statistical analysis}

All the quantitative values are presented as means \pm standard error of the mean (SEM). All the experiments were performed with at least three replicates for each group and for at least three independent repeats. One-way analysis of variance (ANOVA)

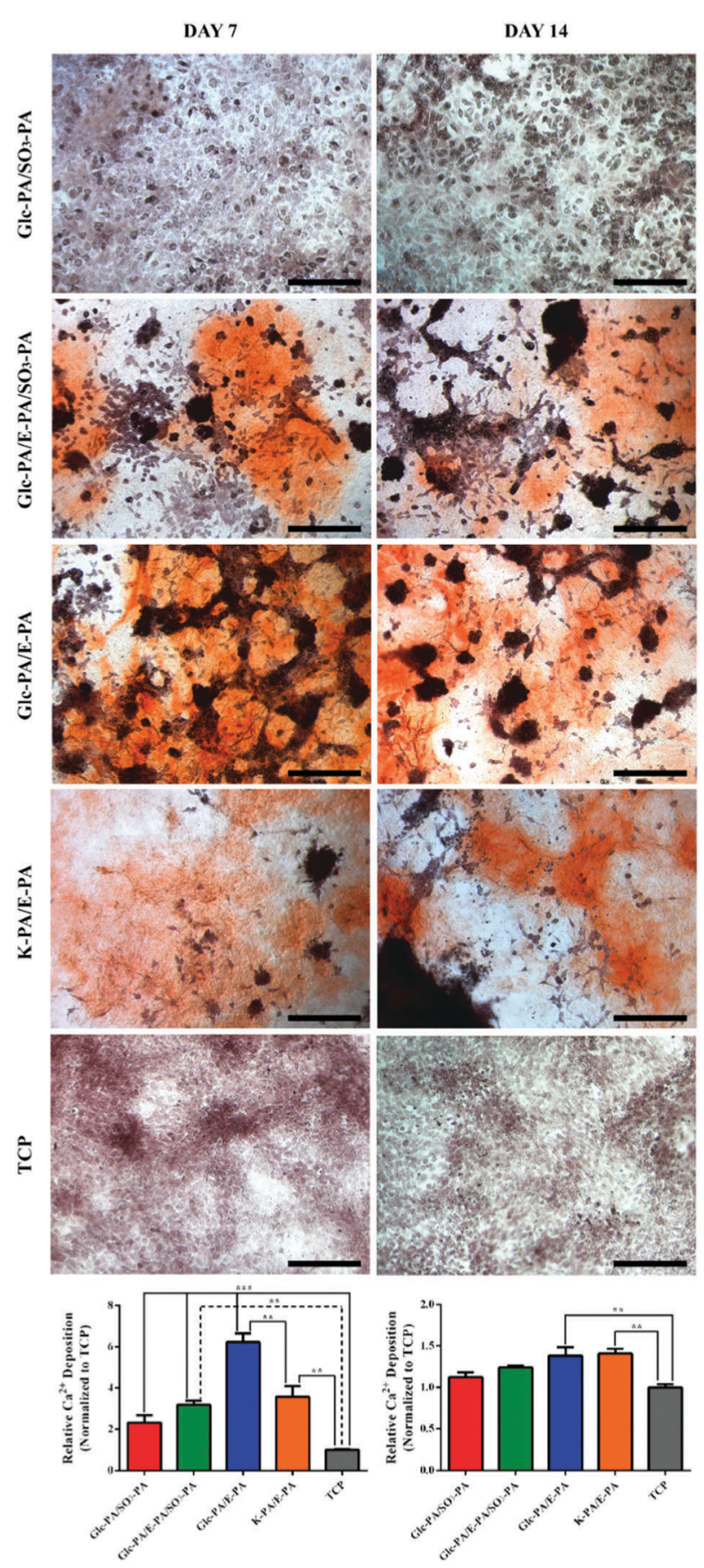

Fig. 5 Day 7 and day 14 Alizarin Red-S staining and their quantitative investigations for calcium deposition analyses when the cells were cultured with growth medium on PA nanofiber networks and uncoated TCP. One-way ANOVA with the Tukey post-test was applied for analyzing the results and significant differences $\left(^{*}\right)$ were expressed as $p<0.05(n=3)$ (scale bars $=200 \mu \mathrm{m}$ ). 
with the Tukey post test was used for statistical analysis and a $p$-value of less than 0.05 was considered statistically significant.

\section{Results and discussion}

Four different PA molecules with different functional groups were designed and synthesized by using the solid phase peptide synthesis method. These PAs were used to form nanofiber networks and to mimic the natural ECM microenvironment. The PAs were designed as a composition of a hydrophobic alkyl group, $\beta$-sheet forming region, and charged group. Lauric acid that was conjugated to the end of the peptide sequences gave a hydrophobic character to the PAs and triggered hydrophobic collapse during self-assembly. ${ }^{37}$ Before the lauric acid coupling, four nonpolar amino acids were incorporated into the peptide sequence to constitute the $\beta$-sheet forming unit (Val-Val-AlaGly). The PA molecules that were used in this study to mimic the GAG components of the natural ECM matrix were Glc-PA [Lauryl-VVAGKS( $\beta$-Glc)-Am], K-PA [Lauryl-VVAGK-Am], E-PA [Lauryl-VVAGE], and $\mathrm{SO}_{3}$-PA [Lauryl-VVAGEK( $p$-sulfobenzoate)Am] (Fig. 1). The Glc-PA and K-PA are positively charged at neutral $\mathrm{pH}$, whereas $\mathrm{SO}_{3}$-PA and E-PA are negatively charged. The Glc-PA was used to form GAG mimetic nanofiber networks by mixing with negatively charged $\mathrm{SO}_{3}$-PA and/or E-PA. Positively charged K-PA was mixed with negatively charged E-PA at neutral $\mathrm{pH}$ to form a non-bioactive control group. By using these PAs, four different nanofiber networks that mimic the sulfonation degrees and glycosylation content of the natural ECM were formed and used in the experiments. These nanofiber networks were Glc-PA/SO $\mathrm{SO}_{3}$-PA, Glc-PA/E-PA/SO $\mathrm{SO}_{3}$-PA, Glc-PA/E-PA, and K-PA/ E-PA. The PA molecules were purified by using HPLC. The purity of the synthesized molecules was determined by using LC-MS (Fig. S1 and S2, ESI $\dagger$ ). All the PA molecules had more than 95\% purity. SEM and TEM analyses showed the nanofibrous structures and the formation of nanofiber networks upon mixing oppositely charged PAs (Fig. 2A, B and Fig. S3, ESI $\dagger$ ).

The CD spectra of the PA combinations revealed a negative minimum at around $220 \mathrm{~nm}$ and a positive maximum at around $200 \mathrm{~nm}$, which indicated the formation of a $\beta$-sheet secondary structure in the Glc-PA/SO $\mathrm{S}_{3}-\mathrm{PA}$, Glc-PA/E-PA/SO ${ }_{3}-\mathrm{PA}$, Glc-PA/E-PA, and K-PA/E-PA combinations (Fig. 2C). The formation of a $\beta$-sheet secondary structure indicates one-dimensional self-assemblies of the peptide amphiphile combinations through intermolecular interactions and formation of nanofibrous networks.

After the chemical and/or physical characterization of the PAs and PA nanofiber networks, an AlamarBlue ${ }^{\circledR}$ assay was used to examine the biocompatibility of each network, including Glc-PA/SO ${ }_{3}$-PA, Glc-PA/E-PA/SO ${ }_{3}$-PA, Glc-PA/E-PA, and K-PA/E-PA, with rat MSCs at $24 \mathrm{~h}$. The AlamarBlue ${ }^{\circledR}$ results showed that the Glc-PA/SO ${ }_{3}$-PA, Glc-PA/E-PA/SO 3 -PA, Glc-PA/E-PA, and K-PA/E-PA nanofiber networks did not alter the viability of rat MSCs compared to an uncoated tissue culture plate (TCP) and provided a biocompatible environment for the cells (Fig. 3A). The proliferation profiles of the rat MSCs on the PA nanofiber networks were analyzed by using the BrdU incorporation assay. ${ }^{38}$ We did not observe a significant difference in proliferation of cells seeded on TCP and K-PA/E-PA nanofiber network at $72 \mathrm{~h}$ which suggests that the cells seeded on the non-bioactive K-PA/E-PA nanofiber network proliferated similarly to the TCP group. However, we observed significant reductions in the proliferation of cells seeded on the Glc-PA/ $\mathrm{SO}_{3}$-PA, Glc-PA/E-PA/SO ${ }_{3}$-PA, and Glc-PA/E-PA nanofiber networks when compared to TCP. These results showed that the cells seeded on the nanofiber networks that contain biological signals either became quiescent or started to differentiate into other lineages. Particularly, the cells seeded on the Glc-PA/SO $\mathrm{SO}_{3}-\mathrm{PA}$ nanofiber network, which contained both glyco and $\mathrm{SO}_{3}$ signals, showed significantly decreased proliferation compared to the Glc-PA/E-PA nanofiber network which only contained glyco signals (Fig. 3B). In addition to viability and proliferation analyses, we examined adhesion and spreading of the rat MSCs on the PA nanofiber networks and uncoated TCP. To test the adhesion, we treated the cells with both BSA and cyclohexamide to block cell adhesion receptors and to prevent protein expression, respectively. After the analysis, we found that all of the PA nanofiber networks facilitated greater cell adhesion than uncoated TCP (Fig. 4). Additionally, under normal cell culture conditions, nearly all rat MSCs readily adhered to uncoated TCP, which suggests that the adhesion was comparable between uncoated TCP and the PA nanofiber networks. Spreading of rat
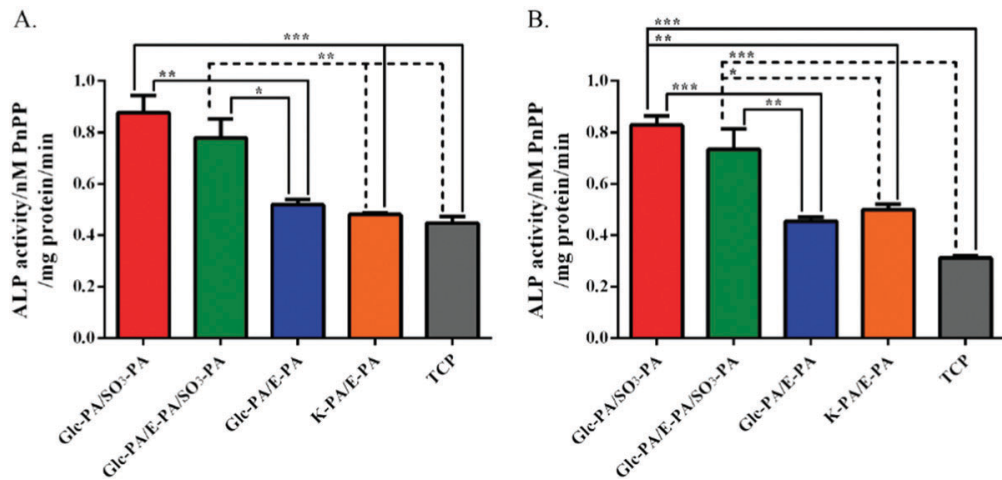

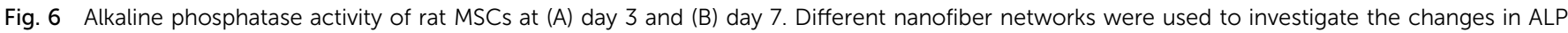

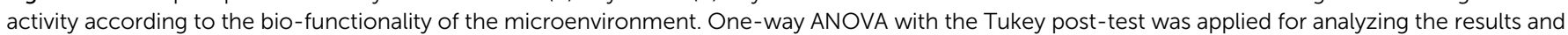
significant differences $(*)$ were expressed as $p<0.05(n=4)$. 
MSCs on the PA nanofiber networks and uncoated TCP was investigated using a confocal microscope after $24 \mathrm{~h}$ of incubation. The analyses demonstrated that the cells seeded on the Glc-PA/ $\mathrm{SO}_{3}$-PA and Glc-PA/E-PA/SO $\mathrm{SO}_{3}$-PA nanofiber networks spread more

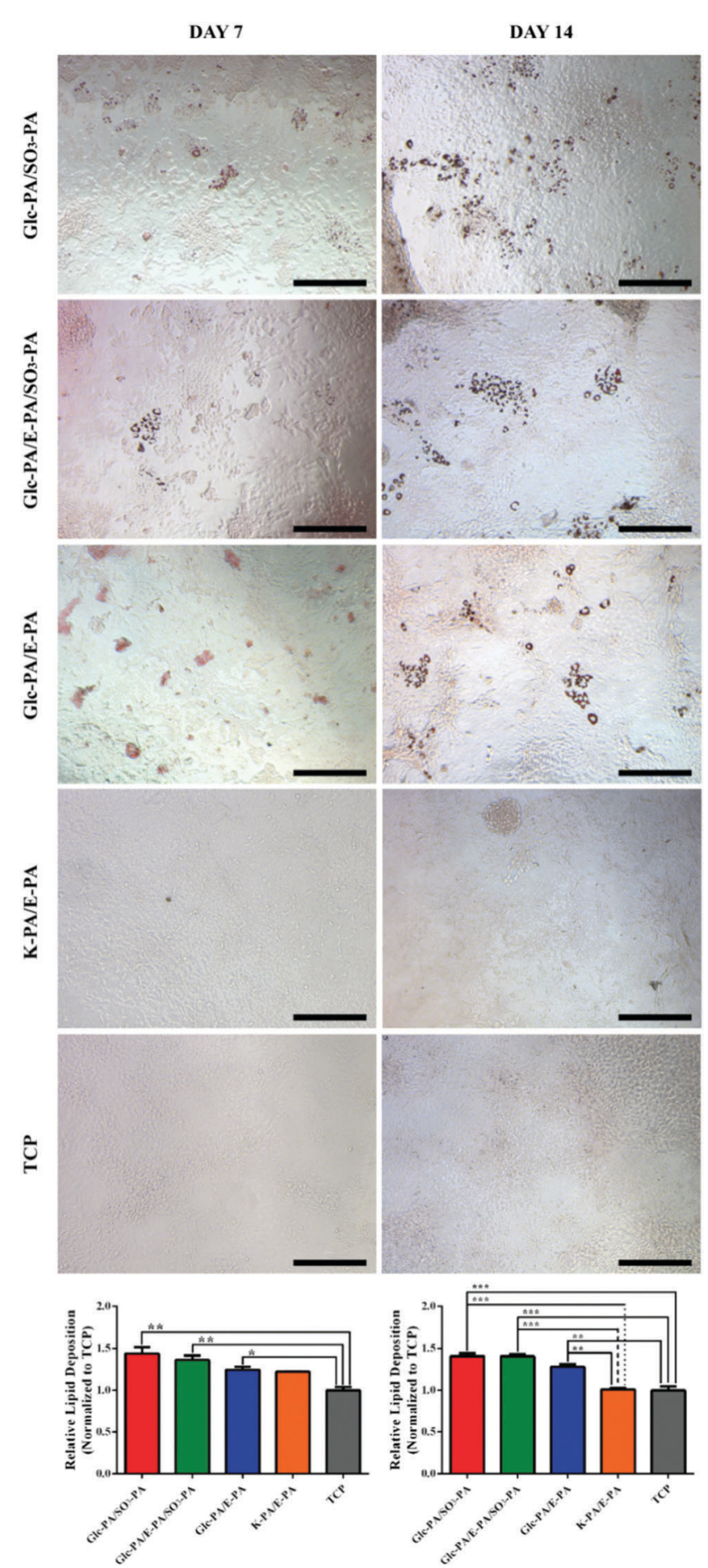

Fig. 7 Day 7 and day 14 Oil Red $O$ staining and their quantitative investigations for lipid deposition analyses. Rat MSCs were cultured with growth medium on PA nanofiber networks and uncoated TCP. One-way ANOVA with the Tukey post-test was applied for analyzing the results and significant differences $\left(^{*}\right)$ were expressed as $p<0.05(n=3)$ (scale bars $=$ $200 \mu \mathrm{m})$. than the ones seeded on the Glc-PA/E-PA and K-PA/E-PA nanofiber networks. However, compared to uncoated TCP, they showed significantly less spreading characteristics due to either becoming quiescent or starting to differentiate into other lineages.

After the analyses of the PA nanofiber networks' effects on the viability, proliferation, adhesion, and spreading of rat MSCs, we investigated the differentiation tendency of the cells on these nanofibrous networks. First, we used Alizarin Red-S staining to qualitatively and quantitatively analyze the differentiation fate of rat MSCs toward the osteogenic lineage. ${ }^{39}$ Both on day 7 and day 14, the rat MSCs seeded on the Glc-PA/E-PA/SO $\mathrm{S}_{3}-\mathrm{PA}$, Glc-PA/ E-PA, and K-PA/E-PA nanofiber networks started to accumulate calcium ions, which is an indicator of osteogenic differentiation. However, there was no significant calcium deposition over the Glc-PA/SO $\mathrm{SO}_{3}$-PA network and TCP (Fig. 5). Alizarin Red-S staining

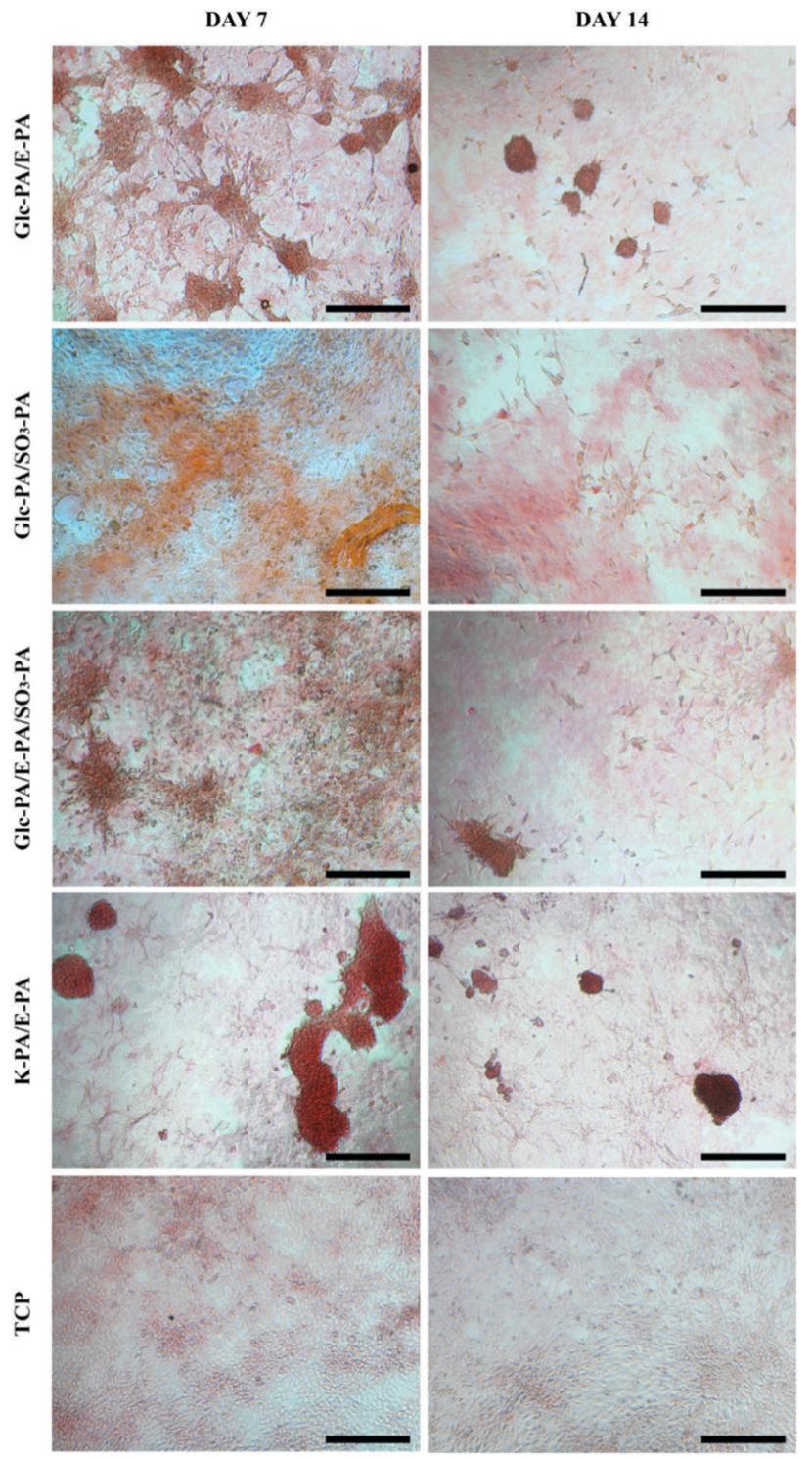

Fig. 8 Day 7 and day 14 Safranin-O staining for the sulfated GAG incorporation analyses. Rat MSCs were cultured in growth medium on PA nanofiber networks and uncoated TCP (scale bars $=200 \mu \mathrm{m}$ ). 
over peptide coated wells that did not contain cells was also performed to study nonspecific staining, which was observed to be negligible (Fig. S5, ESI $\dagger$ ). In light of these results, we decided to check the alkaline phosphatase activity of the cells to investigate their differentiation tendency.

Alkaline phosphatase (ALP) is a hydrolase enzyme that is responsible for the removal of phosphate groups to produce inorganic phosphate. ${ }^{40,41}$ The ALP activity of the rat MSCs was measured on day 3 and day 7, while the cells were cultured with growth medium. Enhanced ALP activities were observed in the cells seeded on the Glc-PA/SO $\mathrm{SO}_{3}-\mathrm{PA}$ and Glc-PA/E-PA/SO $/ \mathrm{SO}_{3}-\mathrm{PA}$ nanofiber networks both at day 3 and day 7 compared to other nanofiber networks and uncoated TCP (Fig. 6). Even though the ALP activity is primarily an osteogenic differentiation marker, it can also be detected in preadipocytes and during adipogenic differentiation of MSCs. ${ }^{42-45}$ Therefore, the increment in the ALP activity level might also be due to the adipogenic differentiation of the rat MSCs cultured on the PA nanofiber networks.

To investigate whether the increase in the ALP activity was due to adipogenic differentiation or not, Oil Red-O staining was performed to visualize neutral triglyceride and lipid accumulation by rat MSCs cultured on the different PA nanofiber networks and uncoated TCP. ${ }^{46}$ The presence of glucose residues in the PA networks enhanced accumulation of neutral lipid vacuoles, which was a sign of adipogenic differentiation. Furthermore, we demonstrated that the addition of sulfonate and carboxylate residues into these functionalized platforms also contributed to adipogenic differentiation. Previously, heparin was shown to promote adipocyte differentiation due to its dose dependent inhibitory effects on differentiation of osteoblasts in vitro and inhibitory effects on the formation of bone in vivo. ${ }^{47,48} \mathrm{We}$ observed that the lipid accumulation started on day 7 over the Glc-PA/SO $\mathrm{SO}_{3}$-PA and Glc-PA/E-PA/SO $\mathrm{SO}_{3}$-PA nanofiber networks, and osteogenic differentiation of the rat MSCs was reduced at this period because of the presence of glucose residues. We did not observe any lipid accumulation over the K-PA/E-PA nanofiber network and uncoated tissue culture plates, probably because these groups did not contain functional groups that support adipogenic differentiation. We also observed that the significant difference in lipid accumulation between all the glucose containing nanofiber networks and TCP increased from day 7 to day 14, which was an indicator of the continuum of adipogenic differentiation (Fig. 7).

Safranin-O staining was performed in order to investigate the sulfated GAG accumulation by rat MSCs, which were seeded over different PA nanofiber networks and uncoated TCP. Safranin-O staining is used for the detection of chondrogenic differentiation. ${ }^{49,50}$ Here, we analyzed the sulfated GAG depositions on the PA nanofiber networks at day 7 and day 14, while the cells were cultured in growth medium. Positive Safranin-O staining of
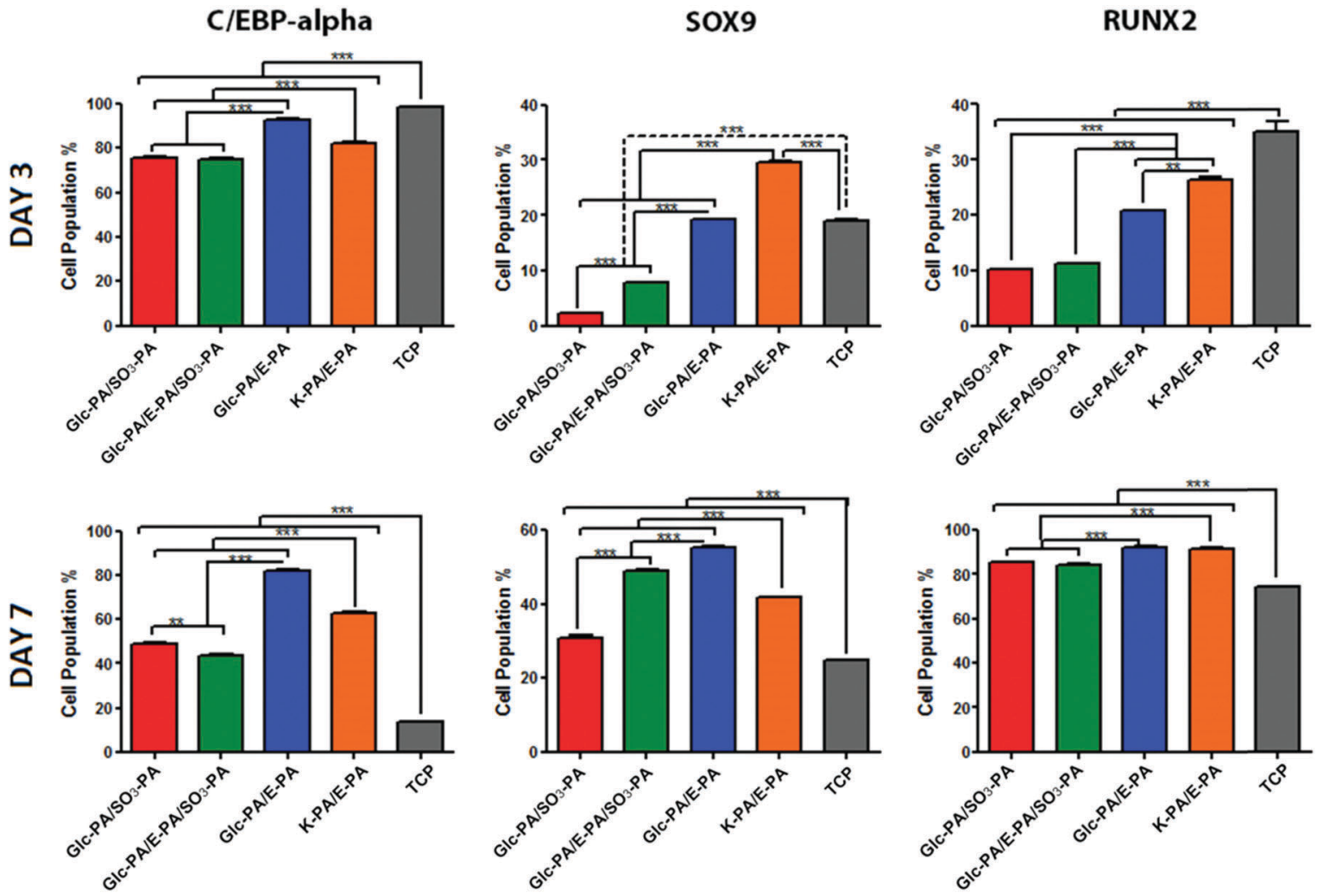

Fig. 9 Day 3 and day 7 protein expression analyses of rat MSCs cultured on different PA nanofiber networks and uncoated TCP. C/EBP-alpha protein expression was investigated for adipogenic differentiation, SOX9 protein expression was investigated for chondrogenic differentiation, and RUNX2 protein expression was investigated for osteogenic differentiation by flow cytometry. One-way ANOVA with the Tukey post-test was applied for analyzing the results and significant differences $(*)$ were expressed as $p<0.05(n=3)$. 
nodule like structures was observed over the Glc-PA/E-PA and K-PA/ E-PA nanofiber networks at day 7 and day 14 (Fig. 8). We did not observe any cell aggregation, or positive Safranin-O staining over the Glc-PA/ $\mathrm{SO}_{3}-\mathrm{PA}$ nanofiber network. These results demonstrated that rat MSCs differentiate towards the chondrogenic lineage over Glc-PA/E-PA and K-PA/E-PA nanofibers, but not over TCP or Glc-PA/ $\mathrm{SO}_{3}$-PA nanofibers.

Finally, the protein expression profiles of the rat MSCs cultured on the PA nanofiber networks and uncoated TCP were analyzed in order to understand the molecular level effects of the PA nanofiber networks on the differentiation fate of the cells. The expression levels of three different proteins were investigated to understand the differentiation fates of the rat MSCs seeded over the PA nanofiber networks. The proteins were transcription factor $S O X-9$ (SOX9), runt-related transcription factor 2 (Runx2) and CCAAT-enhancer-binding protein alpha $(\mathrm{C} / \mathrm{EBP}-\alpha)$. The protein expression levels of SOX-9 and RUNX2 were investigated to understand the osteo/chondrogenic differentiation of the rat MSCs. The protein expression level of $\mathrm{C} / \mathrm{EBP}-\alpha$ was investigated to understand the adipogenic differentiation of the rat MSCs. The protein expression analyses, which were investigated by using flow cytometry, further demonstrated that the presence of Glc-PA in the nanofiber networks stimulates the osteo/chondrogenic differentiation of the rat MSCs. On the other hand, the presence of $\mathrm{SO}_{3}$-PA in the nanofiber networks triggers adipogenic differentiation of the rat MSCs in a dose-dependent manner (Fig. 9).

\section{Conclusion}

The microenvironment of the cells is composed of various fibrous proteins and GAGs in the form of proteoglycans. It is crucial to mimic the GAG content of the ECM to control the differentiation fate of MSCs. In this study, we used supramolecular assemblies of PA molecules in order to mimic the glycosylation and various degrees of sulfation of natural ECM. We observed that conjugation of a glucose moiety on the peptide nanofiber networks enhanced osteo/chondrogenic differentiation of rat MSCs, as shown quantitatively by both Alizarin Red-S staining, and SOX9 and RUNX2 protein expressions investigated by flow cytometry. On the other hand, the addition of sulfonate groups to glucose bearing peptide nanofibers directed differentiation more towards the adipogenic lineage and increased both ALP activity and lipid accumulation. Overall, these results show that distinct biological signals can be presented to the cells on synthetic ECM mimetic PA nanofiber networks composed of different functional side groups, and the fate of rat MSCs can be controlled over these supramolecular peptide nanofibrous networks that provide ECM like microenvironments for the cells even without supplying additional differentiation medium components.

\section{Conflict of Interest}

The authors declare no competing financial interests.

\section{Acknowledgements}

The authors would like to thank Z. Erdogan, M. Guler, and Z. E. Ulger for their technical help. The authors also thank I. C. Garip and Y. Tumtas for their fruitful discussions. M. O. G. and A. B. T. acknowledge partial support from the Turkish Academy of Sciences Distinguished Young Scientist Award (TUBA-GEBIP) and TUBITAK 113 T045.

\section{References}

1 F. Rosso, A. Giordano, M. Barbarisi and A. Barbarisi, J. Cell. Physiol., 2004, 199, 174-180.

2 D. A. Bender, R. K. Murray, K. M. Botham, P. J. Kennelly, V. W. Rodwell and P. A. Weil, Harper's Illustrated Biochemistry, United States of America, 26th edn, 2003, ch. 48.

3 J. D. S. Antonio, B. M. Winston and R. S. Tuan, Dev. Biol., 1987, 123, 17-24.

4 A. Gorio, E. Lesma, L. Vergani and A. M. Di Giulio, Eur. J. Neurosci., 1997, 9, 1748-1753.

5 D. Nikitovic, A. Zafiropoulos, G. N. Tzanakakis, N. K. Karamanos and A. M. Tsatsakis, Anticancer Res., 2005, 25, 2851-2856.

6 K. Norrby and J. Sorbo, Int. J. Exp. Pathol., 1992, 73, 147-155.

7 R. Sasisekharan, Z. Shriver, G. Venkataraman and U. Narayanasami, Nat. Rev. Cancer, 2002, 2, 521-528.

8 A. Johnson, B. Alberts and J. Lewis, et al., Molecular Biology of the Cell, Garland Science, New York, 4th edn, 2002.

9 F. Barry, R. E. Boynton, B. Liu and J. M. Murphy, Exp. Cell Res., 2001, 268, 189-200.

10 S. P. Bruder, N. Jaiswal, N. S. Ricalton, J. D. Mosca, K. H. Kraus and S. Kadiyala, Clin. Orthop. Relat. Res., 1998, 247-256.

11 A. I. Caplan and S. P. Bruder, Trends Mol. Med., 2001, 7, 259-264.

12 A. M. Mackay, S. C. Beck, J. M. Murphy, F. P. Barry, C. O. Chichester and M. F. Pittenger, Tissue Eng., 1998, 4, 415-428.

13 M. F. Pittenger, A. M. Mackay, S. C. Beck, R. K. Jaiswal, R. Douglas, J. D. Mosca, M. A. Moorman, D. W. Simonetti, S. Craig and D. R. Marshak, Science, 1999, 284, 143-147.

14 F. P. Barry, Birth Defects Res., Part C, 2003, 69, 250-256.

15 C. Dombrowski, S. J. Song, P. Chuan, X. Lim, E. Susanto, A. A. Sawyer, M. A. Woodruff, D. W. Hutmacher, V. Nurcombe and S. M. Cool, Stem Cells Dev., 2009, 18, 661-670.

16 T. Helledie, C. Dombrowski, B. Rai, Z. X. H. Lim, I. L. H. Hin, D. A. Rider, G. S. Stein, W. Hong, A. J. Van Wijnen, J. H. Hui, V. Nurcombe and S. M. Cool, Stem Cells Dev., 2012, 21, 1897-1910.

17 D. S. W. Benoit, M. P. Schwartz, A. R. Durney and K. S. Anseth, Nat. Mater., 2008, 7, 816-823.

18 A. Higuchi, Q.-D. Ling, Y. Chang, S.-T. Hsu and A. Umezawa, Chem. Rev., 2013, 113, 3297-3328.

19 A. Higuchi, Q.-D. Ling, S. S. Kumar, Y. Chang, A. A. Alarfaj, M. A. Munusamy, K. Murugan, S.-T. Hsu and A. Umezawa, J. Mater. Chem. B, 2015, 3, 8032-8058.

20 J. M. Anderson, M. Kushwaha, A. Tambralli, S. L. Bellis, R. P. Camata and H. W. Jun, Biomacromolecules, 2009, 10, 2935-2944. 
21 E. Arslan, I. C. Garip, G. Gulseren, A. B. Tekinay and M. O. Guler, Adv. Healthcare Mater., 2014, 3, 1357-1376.

22 G. Gulseren, I. C. Yasa, O. Ustahuseyin, E. D. Tekin, A. B. Tekinay and M. O. Guler, Biomacromolecules, 2015, 16, 2198-2208.

23 J. D. Hartgerink, E. Beniash and S. I. Stupp, Science, 2001, 294, 1684-1688.

$24 \mathrm{H}$. Hosseinkhani, M. Hosseinkhani and H. Kobayashi, Biomed. Mater., 2006, 1, 8-15.

25 M. Sever, B. Mammadov, M. O. Guler and A. B. Tekinay, Biomacromolecules, 2014, 15, 4480-4487.

26 S. Ustun Yaylaci, M. Sardan Ekiz, E. Arslan, N. Can, E. Kilic, H. Ozkan, I. Orujalipoor, S. Ide, A. B. Tekinay and M. O. Guler, Biomacromolecules, 2016, 17, 679-689.

27 J. D. Hartgerink, E. Beniash and S. I. Stupp, Proc. Natl. Acad. Sci. U. S. A., 2002, 99, 5133-5138.

28 H. Cui, M. J. Webber and S. I. Stupp, Biopolymers, 2010, 94, 1-18.

29 D. A. Harrington, E. Y. Cheng, M. O. Guler, L. K. Lee, J. L. Donovan, R. C. Claussen and S. I. Stupp, J. Biomed. Mater. Res., Part A, 2006, 78, 157-167.

30 K. M. Galler, A. Cavender, V. Yuwono, H. Dong, S. Shi, G. Schmalz, J. D. Hartgerink and R. N. D'Souza, Tissue Eng., Part A, 2008, 14, 2051-2058.

31 M. J. Webber, J. Tongers, M. A. Renault, J. G. Roncalli, D. W. Losordo and S. I. Stupp, Acta Biomater., 2010, 6, 3-11.

32 R. Mammadov, B. Mammadov, S. Toksoz, B. Aydin, R. Yagci, A. B. Tekinay and M. O. Guler, Biomacromolecules, 2011, 12, 3508-3519.

33 S. Ustun, A. Tombuloglu, M. Kilinc, M. O. Guler and A. B. Tekinay, Biomacromolecules, 2013, 14, 17-26.

34 S. Kocabey, H. Ceylan, A. B. Tekinay and M. O. Guler, Acta Biomater., 2013, 9, 9075-9085.
35 G. Uzunalli, Y. Tumtas, T. Delibasi, O. Yasa, S. Mercan, M. O. Guler and A. B. Tekinay, Acta Biomater., 2015, 22, 8-18.

36 C. M. Stanford, P. A. Jacobson, E. D. Eanes, L. A. Lembke and R. J. Midura, J. Biol. Chem., 1995, 270, 9420-9428.

37 K. L. Niece, J. D. Hartgerink, J. J. J. M. Donners and S. I. Stupp, J. Am. Chem. Soc., 2003, 125, 7146-7147.

38 F. Dolbeare, H. Gratzner, M. G. Pallavicini and J. W. Gray, Proc. Natl. Acad. Sci. U. S. A., 1983, 80, 5573-5577.

39 H. Puchtler, S. N. Meloan and M. S. Terry, J. Histochem. Cytochem., 1969, 17, 110-124.

40 J. L. Millán, Mammalian Alkaline Phosphatases, 2006, p. 1, DOI: $10.1002 / 3527608060$.

41 W. N. Addison, F. Azari, E. S. Sørensen, M. T. Kaartinen and M. D. McKee, J. Biol. Chem., 2007, 282, 15872-15883.

42 A. T. Ali, C. B. Penny, J. E. Paiker, G. Psaras, F. Ikram and N. J. Crowther, Anal. Biochem., 2006, 354, 247-254.

43 A. T. Ali, C. B. Penny, J. E. Paiker, C. Van Niekerk, A. Smit, W. F. Ferris and N. J. Crowther, Clin. Chim. Acta, 2005, 354, 101-109.

44 P. Bianco, M. Costantini, L. C. Dearden and E. Bonucci, Br. J. Haematol., 1988, 68, 401-403.

45 M. Köllmer, J. S. Buhrman, Y. Zhang and R. A. Gemeinhart, J. Dev. Biol. Tissue Eng., 2013, 5, 18.

46 J. L. Ramírez-Zacarías, F. Castro-Muñozledo and W. KuriHarcuch, Histochemistry, 1992, 97, 493-497.

47 H. J. Hausser and R. E. Brenner, J. Cell. Biochem., 2004, 91, 1062-1073.

48 W. Luo, H. Shitaye, M. Friedman, C. N. Bennett, J. Miller, O. A. MacDougald and K. D. Hankenson, Exp. Cell Res., 2008, 314, 3382-3391.

49 L. Rosenberg, J. Bone Jt. Surg., Am. Vol., 1971, 53, 69-82.

50 P. A. Banaszkiewicz and D. F. Kader, Classic Papers in Orthopaedics, 2014, ch. 110, p. 434, DOI: 10.1007/978-1-4471-5451-8. 